\title{
Factors Predicting Integration of E-Learning by Preservice Science Teachers: Structural Model Development and Testing
}

\author{
Cecilia Temilola Olugbara and Moeketsi Letseka \\ Unesco Chair on ODL, University of South Africa, South Africa \\ kemiolugbara@gmail.com \\ letsem@unisa.ac.za \\ DOI: 10.34190/JEL.18.5.005
}

\begin{abstract}
This study investigated the possible factors that predict e-learning integration into the teaching and learning of science subjects among preservice science teachers. A unified e-learning integration model was developed in which factors such as attitude, intention, skill and flow experience served as precursors of e-learning integration. This was done to help close the gap that no previous studies have developed a structural model to statistically explain the interactions among the most influential factors in various technology integration models. The survey method was used to gather data from 100 preservice science teachers and partial least square structural equation modelling technique was applied for structural path analysis and testing of the developed model. Results revealed a good model fit and hypotheses formulated in this study were faithfully supported. The results also revealed that all factors investigated were found to be significant predictors of elearning integration with skill standing out as the most significant and strongest factor that predicts the integration of elearning by preservice science teachers.
\end{abstract}

Keywords: E-learning Integration, Least Square, Planned Behaviour, Preservice Teachers, Structural Model, Technology Adoption

\section{Introduction}

The ever-growing and emergent roles of information communication technology (ICT) such as e-learning in education system across the world has increased the expectations and curiosity of teachers to seamlessly integrate technology for quality and innovative teaching, learning and assessment in the schools (Sadaf, 2013; Saltan and Arslan, 2017). Against this background, many governments across the nations of the world have invested heavily and made considerable capital investments through several initiatives to provide a variety of interventions to help teachers integrate e-learning into teacher education programmes and schools (Ziphorah, 2014; Adu Gyamfi, 2016). Despite these investments, the uptake of e-learning integration by teachers in South Africa schools is still very low, especially in teaching and learning of mathematics and science subjects, where elearning tools can be used for concretizing scientific abstract concepts (Howie and Blignaut, 2009; Mofokeng and Mji, 2010; Stols, et al., 2015; Umugiraneza, Bansilal and North, 2018). For this important reason, Jita (2016) and Adu Gyamfi (2016) expressed concern that for effective e-learning integration to take place in schools, a solid foundation must be laid properly at the level of preservice teachers who are expected to be part of the innovation change process in schools.

Thus far, literature has generally revealed that despite several inherent benefits of e-learning, preservice teachers are not integrating it during their teaching practices in schools (Al-Ruz and Kahsawneh 2011; Ziphorah, 2014; Prasojo, et al., 2018). The reason behind their inability to integrate e-learning could depend on factors that predict integration behaviour of preservice teachers (Tezci, 2011; Bozkurt, 2016; Olugbara, et al., 2019). However, there has been a paucity of research investigating factors that influence e-learning integration by preservice science teachers in many developing countries of the world (Jita, 2018). Many researchers such as Ajzen (1991), Knezek, et al., (2000), Lee (2010) and Teo (2011) have developed an integrated model to help in explaining technology integration. However. no previous studies have developed a model to explain the interactions among the most influential factors in various technology integration models to compete with one another for predicting e-learning integration. The overarching aim of this study is to propose and test a model to predict e-learning integration by preservice science teachers. The factors contained in this model were the most influential factors in the preceding technology integration models that predict technology. However, these factors have been coherently agglutinated for the first time into a unified structural model to uncover the salient factors that would best predict the integration of e-learning by preservice science teachers.

The remainder of this current paper is succinctly articulated as follows. Section 2 discusses the related literature that are of immediate relevance to the current study. Section 3 presents the theoretical foundation that has 
guided the development of the proposed structural model and the research hypotheses. Section 4 presents the study methods, highlighting data collection and analysis. The details of the results are presented in Section 5. In section 6, discussions of results are presented and discussion on the implication, limitation, and conclusion of the paper is advanced in section 7 .

\section{Literature Review}

\subsection{Integration of E-Learning by Preservice Teachers}

Teaching in the $21^{\text {st }}$ century entails that teachers integrate e-learning technologies into teaching and learning (Batane and Ngwako, 2017). Therefore, it becomes imperative for preservice teachers who are generally regarded as digital natives to integrate e-learning technologies in their teaching, learning and assessment process. Several studies have established that preservice teachers are not integrating e-learning in the delivery of their lessons because of several underlying factors that influence them to integrate or not to integrate elearning in schools (Al-Ruz and Khasawneh, 2011; Batane and Ngwako, 2017; Prasojo, et al., 2018). For example, Agyei and Voogt (2011) explored the potential of will, skill, tool (WST) model to predict Information Communication Technology (ICT) integration of preservice science and mathematics teachers at the University of Cape Coast. The study reported low level of ICT integration into lessons by preservice teachers because of their low ICT skill and access levels of ICT. In a similar attempt, Sedega, et al., (2018) conducted a study to explore the perceptions of preservice teachers on factors affecting their integration of ICT in teaching and learning of Mathematics. The study revealed that preservice teachers did not integrate technology in their lesson because of limited skill to do so.

However, having skill does not guarantee that preservice teachers will always integrate technology, there are some other essential factors that needs to be considered. A number of researchers have pointed out that the attitude of preservice teachers can play a significant role among the factors that affect the successful integration of technology in the classroom (Adu Gyamfi, 2017; Teo, 2009). Knezek, Christensen and Fluke (2003) tested the WST model with high school teachers and argued that at the highest stage of technology integration by teachers in the classroom, attitude to push forward influence ICT integration over ICT skills. The authors were of the view that ICT integration involves a set of well-defined stages, which requires that a teacher must first develop positive attitude rather than acquisition of ICT skills. In addition, Adu Gyamfi (2017) found that preservice teachers who showed positive attitude towards ICT felt more comfortable using ICT, and more intrinsically motivated to integrate it into their teaching. Another study by Teo (2009) among Singapore preservice teachers concluded that negative attitude towards ICT was a deterrent to integrating e-learning by the preservice teachers in the learning environment.

However, Gotkas, Yildrim and Yildrim (2009) disputed this claim arguing that having a positive attitude towards ICT is not sufficient by itself to achieve effective and meaningful integration of ICT into classroom environment. Other important factors such as motivation, skill, intention, access and leadership support do play a pivotal role. In the same vein, Morales (2007) when testing the WST model to predict ICT integration argued that attitude of teachers to use technology are pointless if it is not supported by the necessary skills to use the technology. That is, attitude must be agglutinated with skills for technology integration to be effective. Moreover, technology integration by preservice teachers can be influenced by other factors, such as intention (Teo and Lee, 2010; Teo and Tan, 2012). This avowal is well supported by theory of planned behaviour (TPB). Teo and Tan (2012) applied TPB to explain the intention of 293 preservice teachers to use technology at a teacher training institute in Singapore. The results explained $51 \%$ of the variance in intention of the preservice teachers to use technology. The one apparent limitation of this study is that the authors did not investigate whether the preservice teacher translate their intentions to actual integration. Sadaf (2013) investigated factors that influence the integration of Web 2.0 technologies by preservice teachers during their student teaching experiences. Results of the study revealed a significant positive relationship between intentions and the actual integration of Web 2.0. The results further revealed that some preservice teachers were unable to integrate Web 2.0 because of limited access to technology resources such as connectivity, suitable platform and lack of support from teachers who were not accepting new technologies.

Therefore, intention may not directly translate to the actual integration of e-learning (Olugbara, et al., 2019). Guillén-Gámez, Lugones and Mayorga-Fernández (2019) asserted that willingness and motivation are key elements for preservice teachers to succeed in integrating ICT in the classroom. Batane and Ngwako (2017) studied the problem associated with the integration of technology by 52 preservice teachers during teaching 
practice. The study results indicated that the majority of the participants did not integrate technology in the delivery of their lessons, even though they had enough skills to do so. They were not motivated to integrate technology because there was lack of adequate resources in the classrooms and integrating technology was not part of the assessment for them to pass teaching practice examination which was their ultimate goal. The review of previous studies indicates the significance of searching for factors that might best predict e-learning integration by preservice teachers. A common understanding of these factors have been established, that is factors that predict integration of e-learning by preservice teachers have not been agreed upon.

\subsection{Preparing Preservice Teachers for E-Learning Integration}

Having established the need to understand factors that predict the integration of e-learning in the classroom by preservice teachers. The concern of teacher education institutions should focus on measures of how to prepare preservice teachers for technology integration to make innovate use of technology in a classroom which have been seen as part of the development of teacher education programme. There are many views on what the preparation of preservice teachers should include to increase the possibility of e-learning integration in classrooms. Prasojo, et al., (2018) suggested that technology related training can play a crucial role in preparing preservice teachers for integrating e-learning. Guillén-Gámez, Lugones and Mayorga-Fernándeez (2019) also suggested that teacher education institutions should focus on the training of preservice teachers based on motivation and ensuring that they see the real benefit of using ICT to cause innovation in teaching and improve the quality of education (Olugbara, et al., 2019). The literature has shown that even when teachers are adequately trained to integrate technology, it is still not a guarantee that they would integrate technology (Batane and Ngwako, 2017; Nkula and Krauss, 2014; Sadeck and Cronjé, 2017). On this basis, Ndlovu and Lawrence (2012) explained that the fact that teachers struggle to innovatively use the skills they acquired from the trainings in their lessons to improve learning is an evidence that the training does not adequately prepare the teachers to integrate ICT pedagogically. On the other hand, Nkula and Krauss (2014) argued that even though some teachers have received training on ICT integration, they may still not integrate, because they are not inclined to do so. Consequently, they are resilient to change their old pedagogies, and this may also be associated with their individual factors such as personal preference and attitude to ICT integration, which are not easily resolved.

Moreover, preparing preservice teachers to effectively integrate technology in the classroom is an arduous task that is confronting teacher education institutions (Liu, 2016). Therefore, teacher education institutions have a substantial role to play in preparing preservice teachers to integrate technology into curriculum. To address this challenge, scholars such Tondeur, et al., 2016; Batane and Ngwako, 2017; Ndlovu and Lawrence, 2012) have revealed that teacher education institutions need to develop a systematic and effective strategies. This should include learning technology by design, using teacher educators as role models and scaffolding authentic technology experiences with the available tools. This will assist preservice teachers to develop skills to help them circumvent the challenges of integrating ICT in their teaching processes. Modern preservice teachers are expected to be leaders of technology application in the curriculum upon their graduation from the universities. They should be able to demonstrate to seasoned contemporaries the new trends in technology for them to gain the necessary expertise (Ward and Overall, 2013). By doing so, newly qualified teachers may not be re-trained in the basic technology skills and integration of e-learning technologies into the curriculum. Thus, to implement effective strategies that can prepare preservice teachers to integrate e-learning tools into the curriculum, it is important to understand the factors that best predict their integration of e-learning and tailor the strategies towards the best factors.

\section{Theoretical Framework}

Many researchers have developed and validated various technology adoption theories and models to understand the predictors of e-learning integration. The model proposed in this study was justified by the extant, eminent and robust theories of the Will, Skill, Tool (WST) of ICT integration (Knezek, et al., 2000), Theory of Planned Behaviour (TPB; Ajzen, 1991), and the Flow Theory (FT; Csikszentmihalyi, 1975). The WST was proposed by Knezek, et al, (2000) to predict the level of ICT integration by teachers to influence academic performance. The model postulates that Will (computer attitude) of the teacher, Skill (ICT competence), and Tools (access to ICT tools) are key elements for a teacher to effectively integrate ICT into classroom practice. The WST model has been used extensively to comprehensively explain the level of teachers and preservice teachers ICT integration into classroom practice (Morales, 2007; Agyei and Voogt, 2011; Knezek, Christensen and Fluke, 2003; Knezek and Christensen, 2016). The TPB was proposed by Ajzen, (1991) as a theory that predicts deliberate behaviour, 
which can be deliberate and planned. TPB postulates that intentions of individuals are the proximal determinants of their behaviours, with intention as a concept to capture the motivation of an individual to perform a given behaviour (Ajzen, 1991). The stronger the intention of an individual to engage in a behaviour, the more likely the individual would perform that behaviour. The TPB was applied in an educational setting to examine the intentions of preservice teachers to integrate technology (Teo and Lee, 2010; Teo and Tan, 2012). The flow theory was proposed by Csikszentmihalyi (1975) as a better way to understand intrinsic motivation. Flow theory posits that the flow experience occurs when people engage and immerse themselves in specific activities (Csikszentmihalyi, 1997). When people are in the flow state, they become totally immersed in their activities to the point of losing an awareness of time and critical matter, unable to recognize changes in their environments that nothing else seems to matter besides what they are doing (Lee, 2010). Some researchers have extensively applied flow theory to explain intentions of teachers and students and the usage of e-learning (Liao, 2006; Lee, 2010; Rodriguez-Ardura and Meseguer-Artola, 2017; Kim and Jang, 2015).

\subsection{Research model and hypotheses}

The research question investigated in this paper deals with the factors that best predict integration of e-learning by preservice science teachers. The proposed model in this study combines the most influential factors reported in the literature to predict technology integration under a single framework to realize a new validated structural model. These influential factors have hitherto not been coherently integrated into a unified structural model to compete with one another to predict e-learning integration. Hence, it is possible that, when these influential factors are combined, they collectively provide a broader understanding of the factors that best predict the integration of e-learning for science education.

\subsubsection{Attitude}

Attitude is defined as positive or negative feelings of someone about using technology to accomplish a given task (Teo and Tan, 2012). The successful integration of e-learning largely depends on the attitudes of teachers who eventually determine how these tools will be used in the classrooms (Afshari, et al., 2009). The attitude and integration relationship in WST suggests that at the highest stage of technology integration by teachers, attitude to push forward was the best predictor. Thus, the willingness of teachers to integrate technology leads to higher stages of classroom ICT integration, which in turn leads to greater student achievement. This relationship has been empirically tested using WST by prior study (Knezek, Christensen and Fluke, 2003). Moreover, according to TPB, attitude predicts behavioural intention of teachers, which in turn influences their actual behaviour. Prior research which applied TPB has demonstrated that attitude is a significant predictor of intention of preservice teachers to integrate e-learning (Teo and Lee, 2010; Teo and Tan, 2012). The following hypotheses were therefore proposed in this study:

$\mathbf{H}_{1}$ : Attitude will be a significant predictor of e-learning integration by preservice science teachers.

$\mathbf{H}_{\mathbf{2}}$ : Attitude will be a significant predictor of intention of preservice science teachers to integrate e-learning.

\subsubsection{Intention}

Intention is the exact decision of a person to behave in a certain way and it guides a motivation to perform behaviour in terms of direction and intensity (Sheeran, 2002). The factor of intention is the most prominent predictor of behaviour in TPB. This argument is supported by Tarhini, Hone and Liu, (2013) who considered intention to be an immediate antecedent of usage behaviour. It gives an indication about the readiness of an individual to perform a specific behaviour. In regard of the relationship between intention and behaviour, researchers have applied TPB to predict intention of preservice teacher to integrate technology in the classroom (Teo and Lee, 2010; Teo and Tan, 2012; Olugbara, et al., 2019). Therefore, the following hypothesis was therefore proposed in this study:

$\mathbf{H}_{3}$ : Intention will be a significant predictor of e-learning integration by preservice science teachers.

\subsubsection{Skill}

Technology skill is defined as the ability of a teacher to use a wide range of varying ICT applications to perform various education tasks (Tondeur, Valcke and Van Braak, 2008). The ICT skill of teachers is a major predictor of ICT integration and lack of it has been reported as inhibitors of ICT integration into teaching practices (Morales, 2007; Mofokeng and Mji, 2010; Agyei and Voogt, 2011). The close link between skill and integration in WST model posits that technology skills of teachers influenced them to integrate ICT in teaching and learning processes. This close link is empirically supported by prior studies that applied WST model to predict the level of ICT integration by teachers and preservice teachers (Morales, 2007; Agyei and Voogt, 2011). Knezek and 
Christensen (2016) have extended the WST model by including pedagogy factor to predict technology integration among teachers. The result indicated that pedagogy was the strongest predictor of technology integration with an $\mathrm{R}^{2}$ of $33 \%$ followed by skill with an $\mathrm{R}^{2}$ of $28 \%$. The results indicated that skill contributed significantly to technology integration. Moreover, Anderson, Groulx and Manibger (2011) found that technology skills of preservice teachers predicted their intention to integrate e-learning frequently in their classrooms. Bordbar (2010) and Babic (2012) discovered that the majority of teachers who showed negative or neutral attitudes towards the integration of ICT into teaching and learning processes lacked the knowledge and skills that would allow them to integrate e-learning in their classrooms. Hence, the following hypotheses were proposed in this study:

$\mathbf{H}_{4}$ : Skill will be a significant predictor of e-learning integration by preservice science teachers.

$\mathbf{H}_{5}$ : Skill will be a significant predictor of intention of preservice science teachers to integrate e-learning.

$\mathbf{H}_{6}$ : Skill will be a significant predictor of attitude of preservice science teachers to integrate e-learning.

\subsubsection{Flow experience}

Flow experience is defined as "the holistic experience that people feel when they act with total involvement" (Csikszentmihalyi, 1997). People experience flow when they are completely engrossed in an activity to the point of losing sense of time and unable to recognize changes in their immediate environments. Flow experience is an intrinsic motivation that can stimulate users to perform an activity with inner joy (Lee, 2010). Most researchers have measured flow experience with two variables, which are concentration and enjoyment. Concentration refers to the degree to which the attention of a person focuses on an activity (Trevino and Webster, 1992). Enjoyment refers to the degree to which ICT usage being perceived to be pleasant, irrespective of the consequences that may arise (Davis, Bagozzi and Warshaw, 1992; Liao, 2006). When preservice teachers use elearning, they may experience flow, as most e-learning tools provide interactive functions such as chat rooms, discussion forum, virtual gaming and entertainment services that may capture their interest and help them to enjoy and concentrate on their learning (Lee, 2010).

Evidences from the literature supports the application of flow experience in explaining e-learning integration, intention, skills and attitude amongst students (Rodriguez-Ardura and Meseguer-Artola, 2017; Lee, 2010; Ro, Guo and Klein, 2018; Liao, 2006). For example, Rodrıguez-Ardura and Meseguer-Artola (2017) investigated the effects of flow in an e-learning environment among 29,723 university undergraduate and graduate students. The results indicated that flow states influence effective continuance usage of e-learning by students and enhance their academic performance. Kim and Jang (2015) indicated that perceived enjoyment was the strongest predictor of integration of Web 2.0 tools by preservice teachers into their teaching and learning processes. Lee (2010) applied the flow theory among 363 students in a Web-based learning service to predict continuance intention of students to use e-learning. The results revealed that flow experience through concentration was a significant predictor of intention of students to use the e-learning service. Mirroring similar outcomes, Teo and Noyes (2011) showed that perceived enjoyment was a significant predictor of intention of preservice teachers to integrate e-learning. The study of Ro, Guo and Klein (2018) examined the effect of flow experience on 315 undergraduate students learning performance. The results revealed that continuous engagement of students in the flow activity developed their skills better in using e-learning, which enhanced their learning performance. Liao (2006) applied flow theory to examine the cause and effect of flow experience on the attitude of 253 undergraduate students to use e-learning systems. The results indicated that students experienced flow and developed positive attitudes towards integrating the e-learning in their module. The following hypotheses were therefore proposed in this study:

$\mathbf{H}_{7}$ : Flow experience will be a significant predictor of e-learning integration by preservice science teachers.

$\mathbf{H}_{\mathbf{8}}$ : Flow experience will be a significant predictor of intention of preservice science teachers to integrate elearning.

$\mathbf{H}_{9}$ : Flow experience will be a significant predictor of skill of preservice science teachers to integrate e-learning.

$\mathbf{H}_{10}$ : Flow experience will be a significant predictor of attitude of preservice science teachers to integrate elearning. 


\subsubsection{E-Learning Integration}

E-learning integration refers to innovative way of using diverse electronic tools to improve teaching, learning and assessment (Olugbara, 2018). From the literature, effective integration of e-learning in the classrooms is determined by the attitude of a teacher toward e-learning and the technology skill of the teacher (Knezek, Christensen and Fluke, 2003; Morales, 2007). How skilful teachers are with technology tools would determine their abilities to integrate it in the classroom. In addition, e-learning integration was found to be predicted by behavioural intention in TPB (Ajzen, 1991). The stronger the intention to perform behaviour, the more likely the behaviour is to be performed. Moreover, Rodriguez-Ardura and Meseguer-Artola (2017) indicated that flow experience influence effective usage of e-learning by preservice teachers. The research hypotheses constitute the proposed e-learning integration model of this study as graphically illustrated in Figure 1.

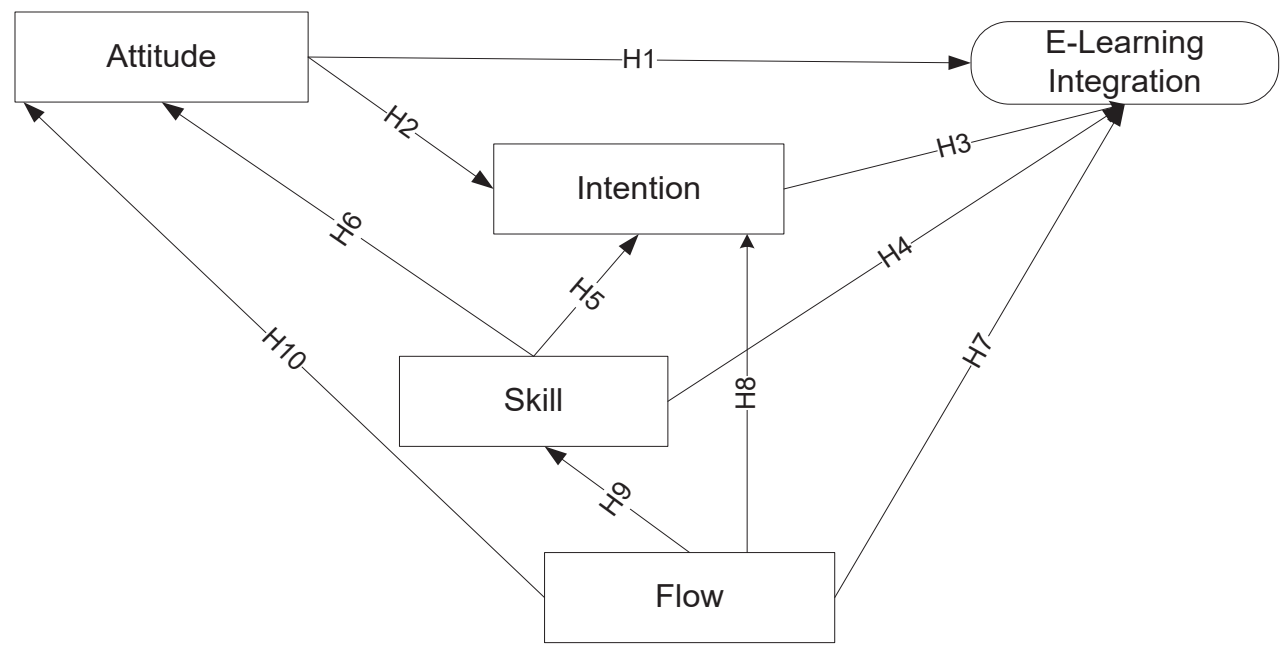

Figure 1: Proposed E-learning Integration Model

\section{Methods}

\subsection{Data collection}

The survey instrument with two sections was used to collect data for this study (Olugbara, 2018). The first section had questions about the demographic profile of the participants, while the second section focused on measuring the model factors. These factors are attitude, intention, skills, flow experience and integration. The scale items for the model were adapted from previous studies (Sadaf, Newby and Ertmer, 2012; Sadaf, 2013; Lee, 2010; Liao and Lu, 2008; Liao, 2006) with slight modifications to fit the specific context of e-learning integration. In addition, each conceptual item corresponding to these factors was measured on a five-point Likert-scale ranging from "strongly agree" (5) to "strongly disagree" (1). One hundred preservice science education students were conveniently and purposively selected from the fourth year batch at the participating University in South Africa to provide answers to the administered survey. These preservice science teachers were selected for this study because they were involved in formal e-learning classes in their different modules and they had recently completed their teaching practice in the high schools, thus, they were expected to provide in-depth information about the study being investigated. Although, first, second and third year preservice science education teachers were also involved in formal e-learning classes in their different modules, they have not been in teaching practice during the data collection process of this study.

\subsection{Data analysis}

The partial least square (PLS) structural equation modelling (SEM) (PLS-SEM) was used to examine the proposed model. It is a statistical tool widely used for structural model development and testing in the education domain (Kalema, Olugbara and Kekwaletswe, 2011; Teo, 2011; Lee, 2010; Olugbara, et al., 2019). SEM allows factors to act as both independent and dependent factor in the model and interact with each other directly or indirectly to predict e-learning integration (Teo, 2011). Data analysis in this styudy comprised two stages. The first stage examined the descriptive statistics of the measurement items and assessed the psychometric reliability and validity properties of the measurement model. The second stage assessed the structural model through the hypothesis testing with a view to ascertaining the strength of relationships among the model factors. The PLS- 
SEM technique was used to develop the path analysis that quantifies the relationships among multiple factors. The PLS-SEM was chosen because it is a variance-based (VB-SEM) that does not require neither a large sample size because it works well on a minimal sample size of 30-100 nor a specific assumption on the data distribution or missing data as it is distribution-free (Chin, 1998; Hair, Ringle and Sarstedt, 2011; Peng and Lai, 2012; Fan et al., 2016; Joseph and Olugbara, 2018). Moreover, the 10-times rule method for PLS path modelling requires the sample size be equal to the larger of either (Henseler, Ringle and Sinkovics, 2009; Goodhue, Lewis and Thompson, 2012; Mohammad and Nazila 2015):

1. Ten times the number of indicators of the scale with the largest number of indicators or

2. Ten times the largest number of independent factors used to determine a dependent factor in the inner path model. Thus, the sample size of 100 preservice science teachers used in this study meets these requirements.

\section{Results}

The study results are presented in this section, under the various sub-headings, which are demographic profile, e-learning usage, descriptive statistics, measurement model and structural model.

\subsection{Demographic Profile}

The research sample of this study consisted of 54 (54\%) female and 46 (46\%) male preservice science teachers. The majority (72\%) of the preservice science teachers (PSSTs) fell in the 21-25 year age range, which fitted the general age profile of undergraduate students at the institution and South African universities. By and large, 20\% of them fell under the 26-30 age group while $8 \%$ were $31-35$ years of age.

\subsection{E-learning usage}

The $39 \%$ of the PSSTs indicated that they used e-learning in their science modules several times each week, $26 \%$ used it several times a day, $20 \%$ at least once in a week and $15 \%$ once in a day. In addition, $30 \%$ indicated that they spent 1-2 hours of using e-learning each week, $28 \%$ spent 3-4 hours each week, $13 \%$ spent $7-8$ hours each week, $12 \%$ spent 5-6 hours each week, 11\% spent 11-12 hours each week and 6\% spent 9-10 hours each week. The result indicated that the majority of the PSSTs were technology savvy. They represented 15 major study areas in their studies in mathematics and life science having the greatest number. In addition, they came from various subject combinations offered in the Department of Mathematics, Science and Technology Education (MSTE).

\subsection{Descriptive statistics}

The mean (M), standard deviations (SD), coefficient of variation (CoV), skewness (SK), and kurtosis (K) values of all the 16 items were computed as shown in Table 1. The mean values fell above the midpoint of 3.0 ranging from 3.54 to 4.63 . The SDs ranged from 0.50 to 1.00, indicating an overall positive response to the factors that were measured in this study and a fairly narrow spread around the mean. The CoV measure expressed on a percentile scale was used to combine the mean and standard deviation for better decision making because the measure is bounded between 0 and 100. It is a ratio of standard deviation to mean to measure the degree of relative variability of items with less emphasis on dimensionality (Olugbara, et al, 2019). All items achieved low CoV below $50 \%$ to indicate that all items have low dispersion from their respective means. The ATT1 and INTE2 have the lowest and highest dispersions respectively. The values of the SK and K for the items were between 1.51 and -0.05 , and -0.83 and 3.49 , respectively. These values were within the recommended cutoffs of 3.0 and 8.0 for skewness and kurtosis, respectively, indicating univariate normality in the data for the purpose of structural equation (Kline, 2010).

Table 1: Factor, item, item description, mean, standard deviation, coefficient of variation, skewness and kurtosis of items

\begin{tabular}{|l|l|l|l|l|l|l|l|}
\hline Factor & Item & \multicolumn{1}{|c|}{ Item description } & M & SD & CoV & SK & K \\
\hline Attitude & ATT1 & $\begin{array}{l}\text { I believe it is a good practice to use e- } \\
\text { learning for teaching and learning }\end{array}$ & 4.63 & 0.51 & 10.93 & -0.79 & -0.83 \\
\cline { 2 - 8 } & ATT2 & $\begin{array}{l}\text { I like the idea of using e-learning to prepare } \\
\text { teaching and learning materials }\end{array}$ & 4.35 & 0.77 & 17.70 & -1.51 & 3.49 \\
\hline Intention & INT1 & $\begin{array}{l}\text { I intend to use e-learning for teaching and } \\
\text { learning }\end{array}$ & 3.75 & 0.91 & 24.37 & -0.45 & -0.14 \\
\cline { 2 - 8 } & INT2 & $\begin{array}{l}\text { I plan to use e-learning for teaching and } \\
\text { learning }\end{array}$ & 4.11 & 0.68 & 16.55 & -0.53 & 0.66 \\
\hline
\end{tabular}




\begin{tabular}{|l|l|l|l|l|l|l|l|}
\hline Factor & Item & \multicolumn{1}{|c|}{ Item description } & M & SD & CoV & SK & K \\
\hline \multirow{5}{*}{ Skill } & INT3 & $\begin{array}{l}\text { I hope to frequently use e-learning for } \\
\text { teaching and learning }\end{array}$ & 4.05 & 0.66 & 16.22 & -0.05 & -0.64 \\
& SKL1 & I am knowledgeable about e-learning & 3.98 & 0.86 & 21.72 & -0.73 & 0.56 \\
\cline { 2 - 8 } & SKL2 & $\begin{array}{l}\text { I know how to use e-learning for teaching } \\
\text { and learning. }\end{array}$ & 4.02 & 0.85 & 21.22 & -0.94 & 1.14 \\
\cline { 2 - 8 } & SKL3 & I know how to operate e-learning functions & 3.75 & 0.90 & 24.08 & -0.66 & 0.16 \\
\cline { 2 - 8 } & SKL4 & $\begin{array}{l}\text { I have the necessary skills to use e-learning } \\
\text { for teaching and learning. }\end{array}$ & 3.73 & 0.95 & 25.52 & -1.01 & 1.17 \\
\hline \multirow{5}{*}{ Flow } & FLW1 & $\begin{array}{l}\text { I enjoy using e-learning as a teaching and } \\
\text { learning assisted tools. }\end{array}$ & 4.17 & 0.78 & 18.68 & -0.70 & 0.12 \\
\cline { 2 - 8 } & FLW2 & $\begin{array}{l}\text { I find it interesting when I use e-learning for } \\
\text { teaching and learning. }\end{array}$ & 4.15 & 0.78 & 18.87 & -0.66 & 0.02 \\
\cline { 2 - 8 } & FLW3 & I find the use of e-learning pleasurable. & 3.93 & 0.84 & 21.48 & -0.28 & -0.72 \\
\cline { 2 - 8 } & FLW4 & $\begin{array}{l}\text { I focus attention on learning when I use e- } \\
\text { learning. }\end{array}$ & 3.86 & 0.85 & 22.10 & -0.42 & -0.35 \\
\hline Integration & INTE1 & I use e-learning frequently for learning. & 4.15 & 0.50 & 12.05 & -0.20 & 3.28 \\
\cline { 2 - 8 } & INTE2 & I use e-learning frequently for assessment. & 3.61 & 1.00 & 27.81 & -0.49 & -0.37 \\
\cline { 2 - 8 } & INTE3 & I use e-learning frequently to collaborate. & 3.54 & 0.92 & 25.85 & -0.57 & 0.05 \\
\hline
\end{tabular}

\subsection{Measurement Model Testing}

The PLS-SEM implementation in the WarpPLS 4.0 software (Kock, 2013) was applied to assess the study measurement in reflective mode. Confirmatory factor analysis was employed to determine the extent to which the reliability and validity values met the standardized criteria. The model reliability was assessed using item reliability and internal consistency reliability. The item reliability was assessed using the item loadings, wherein all the loadings were above the threshold value of 0.70 (Chin, 1998), ranged from 0.712 to 0.879 and were significant at $p<0.001$ level. The internal consistency reliability of each factor was assessed using the composite reliability instead of Cronbach alpha because of the propensity of Cronbach alpha to underestimate reliability (Chin, 1998; Henseler, Ringle and Sinkovics, 2009). The composite reliabilities ranged from 0.757 to 0.879 as reported in Table 2, which exceeded the recommended threshold value of 0.70 (Kock, 2015).

Table 2: Internal consistency reliability (loading) and Composite Reliability (CR)

\begin{tabular}{|l|l|l|l|l|}
\hline Factor & Item & Loading & p-Value & CR \\
\hline \multirow{4}{*}{ Attitude } & ATT1 & 0.848 & $<0.001$ & 0.837 \\
\cline { 2 - 5 } & ATT2 & 0.849 & $<0.001$ & \\
\hline Intention & INT1 & 0.746 & $<0.001$ & 0.838 \\
\hline \multirow{4}{*}{ Skill } & INT2 & 0.875 & $<0.001$ & \\
& INT3 & 0.763 & $<0.001$ & \\
\hline \multirow{5}{*}{ Flow } & SKL1 & 0.745 & $<0.001$ & 0.879 \\
\cline { 2 - 5 } & SKL2 & 0.852 & $<0.001$ & \\
\cline { 2 - 5 } & SKL3 & 0.739 & $<0.001$ & \\
\cline { 2 - 5 } & SKL4 & 0.866 & $<0.001$ & \\
\cline { 2 - 5 } & FLW1 & 0.879 & $<0.001$ & \\
\cline { 2 - 5 } & FLW2 & 0.848 & $<0.001$ & \\
\cline { 2 - 5 } & FLW3 & 0.763 & $<0.001$ & \\
\cline { 2 - 5 } & FLW4 & 0.712 & $<0.001$ & \\
\hline & INTE1 & 0.744 & $<0.001$ & \\
\cline { 2 - 5 } & INTE2 & 0.735 & $<0.001$ & \\
\cline { 2 - 5 } & INTE3 & 0.743 & & \\
\hline
\end{tabular}

The model validity was assessed using the convergent validity and discriminant validity (Urbach and Ahlemann, 2010; Kock, 2015). Convergent validity was measured by the average variance extracted (AVE) test on the factors, which should equal or exceed the recommended threshold value 0.50 (Henseler, Ringle and Sinkovics, 2009). The AVE values for the model factors had an acceptable level of convergent validity that ranged from 0.511 to 0.720 as reported in Table3. Discriminant validity was assessed using the criterion proposed by Fornell and Larcker's (1981), which compares the square root of AVE with the correlation of latent factors. As shown in Table 3, bolder elements represent the square roots of the AVEs, which are greater in all cases than off-diagonal elements in the corresponding rows and columns. Hence, the results showed that discriminant validity was established. 
Table 3: Convergent validity (AVE) and Discrimant validity (Fornell-Larker), square roots of the AVE shown on the diagonal and off-diagonal represent the correlations

\begin{tabular}{|l|l|l|l|l|l|l|}
\hline Factors & AVE & Attitude & Intention & Skill & Flow & Integration \\
\hline Attitude & 0.720 & $\mathbf{0 . 8 4 8}$ & & & & \\
\hline Intention & 0.635 & 0.349 & $\mathbf{0 . 7 9 7}$ & & & \\
\hline Skill & 0.645 & 0.317 & 0.383 & $\mathbf{0 . 8 0 3}$ & & \\
\hline Flow & 0.645 & 0.431 & 0.518 & 0.582 & $\mathbf{0 . 8 0 3}$ & \\
\hline Integration & 0.511 & 0.342 & 0.447 & 0.505 & 0.478 & $\mathbf{0 . 7 1 5}$ \\
\hline
\end{tabular}

\subsection{Structural model Testing}

The structural model was assessed by the coefficient of determination $\left(R^{2}\right)$, significance and relevance of the path coefficients, effect sizes (f2), predictive relevance $\left(Q^{2}\right)$ and Goodness of Fit (GoF) (Urbach and Ahlemann, 2010; Navimipour and Soltani, 2016). The research model explained $44 \%$ of the variance in e-learning integration. More specifically, with an $\mathrm{R}^{2}$ of 0.44 for INTE, four factors (ATT, INT, SKL and FLW) explain $44 \%$ of the variance in INTE as shown in Fig. 2. The model had a moderate explanatory power to predict e-learning integration. In addition, there are some interactive effects among attitude, intention, skills and flow experience on integration. With an $R^{2}$ of 0.32 for INT, three factors (ATT, SKL and FLW) explain $32 \%$ of the variance in INT. With an $\mathrm{R}^{2}$ of 0.21 for ATT, two factors (FLW and SKL) explain $21 \%$ of the variance in ATT. Finally, with an $\mathrm{R}^{2}$ of 0.36 for SKL, FLW explains $36 \%$ of the variance in SKL.

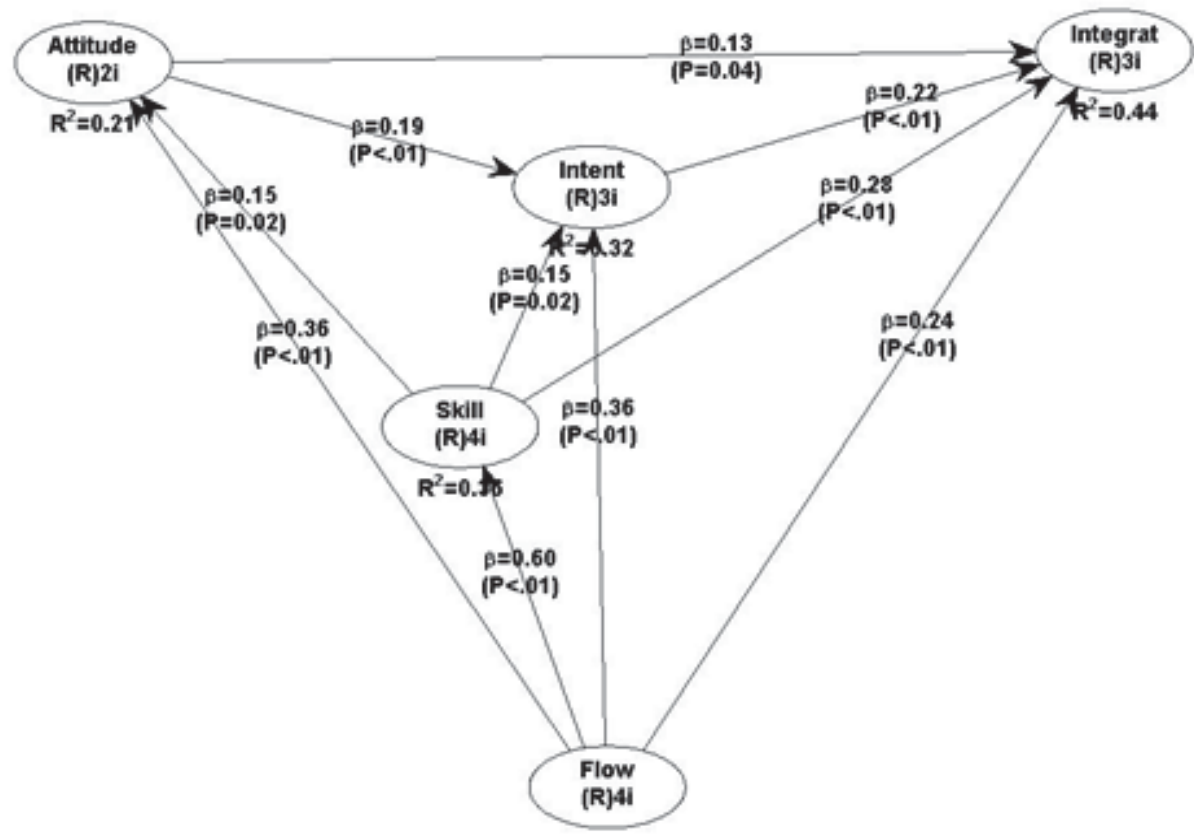

Figure 2: The Hypothesized Structural Results

The results of the structural model showed that all paths were statistically significant and all the research hypotheses were supported as shown in Fig 2 and Table 4. The effect size $\left(f^{2}\right)$ of path links between exogenous and endogenous variables ranged from 0.05 to 0.36 , representing small, medium and large effect sizes as shown in Table 4. The Stone-Geisser $Q^{2}$ predictive relevance value for the endogenous factors are greater than zero as recommended by Hair, et al., (2014), demonstrating that the model has adequate predictive relevance as shown in Table 5). 
Table 4: Summary of hypothesis testing

\begin{tabular}{|c|c|c|c|c|c|c|}
\hline Hypothesis & Path & $\begin{array}{l}\text { Path coefficient } \\
\text { (B) }\end{array}$ & $\begin{array}{l}\text { Significance ( } p \text { - } \\
\text { Value) }\end{array}$ & $\begin{array}{l}\text { Effect size } \\
\left(f^{2}\right)\end{array}$ & Inference & Validation \\
\hline $\mathrm{H}_{1}$ & $\begin{array}{l}\text { Attitude } \rightarrow \\
\text { Integration }\end{array}$ & 0.13 & $0.04^{*}$ & 0.05 & $\begin{array}{l}\text { Small effect } \\
\text { size }\end{array}$ & Yes \\
\hline $\mathrm{H}_{2}$ & $\begin{array}{l}\text { Attitude } \rightarrow \\
\text { Intention }\end{array}$ & 0.19 & $0.007^{* *}$ & 0.07 & $\begin{array}{l}\text { Small to } \\
\text { medium }\end{array}$ & Yes \\
\hline $\mathrm{H}_{3}$ & $\begin{array}{l}\text { Intention } \rightarrow \\
\text { Integration }\end{array}$ & 0.22 & $0.002^{* *}$ & 0.11 & $\begin{array}{l}\text { Small to } \\
\text { medium }\end{array}$ & Yes \\
\hline $\mathrm{H}_{4}$ & $\begin{array}{l}\text { Skill } \rightarrow \\
\text { Integration }\end{array}$ & 0.28 & $0.001^{* *}$ & 0.15 & $\begin{array}{l}\text { Medium effect } \\
\text { size }\end{array}$ & Yes \\
\hline $\mathrm{H}_{5}$ & Skill $\rightarrow$ Intention & 0.15 & $0.024^{*}$ & 0.06 & $\begin{array}{l}\text { Small effect } \\
\text { size }\end{array}$ & Yes \\
\hline $\mathrm{H}_{6}$ & Skill $\rightarrow$ Attitude & 0.15 & $0.024^{*}$ & 0.05 & $\begin{array}{l}\text { Small effect } \\
\text { size }\end{array}$ & Yes \\
\hline $\mathrm{H}_{7}$ & $\begin{array}{l}\text { Flow } \rightarrow \\
\text { Integration }\end{array}$ & 0.24 & $0.001^{* *}$ & 0.13 & $\begin{array}{l}\text { Small to } \\
\text { medium }\end{array}$ & Yes \\
\hline $\mathrm{H}_{8}$ & Flow $\rightarrow$ Intention & 0.36 & $0.001^{* *}$ & 0.19 & $\begin{array}{l}\text { Medium to } \\
\text { large }\end{array}$ & Yes \\
\hline $\mathrm{H}_{9}$ & Flow $\rightarrow$ Skill & 0.60 & $0.001^{* *}$ & 0.36 & $\begin{array}{l}\text { Large effect } \\
\text { size }\end{array}$ & Yes \\
\hline $\mathrm{H}_{10}$ & Flow $\rightarrow$ Attitude & 0.36 & $0.001^{* *}$ & 0.16 & $\begin{array}{l}\text { Medium to } \\
\text { large }\end{array}$ & Yes \\
\hline
\end{tabular}

Path significance: ${ }^{*} p<0.05, * * p<0.01$

Table 5: Predictive relevance of the model

\begin{tabular}{|l|l|}
\hline Factors & Q Square \\
\hline Attitude & 23 \\
\hline Intention & 33 \\
\hline Skill & 37 \\
\hline Integration & 45 \\
\hline
\end{tabular}

The overall predictive power of the model assessed through the Goodness of Fit (GoF) was 0.46, which exceeds the cutoff value of 0.36 for large GoF. The model has a good fit and quality indices (APC, 0.268; ARS, 0.330; AARS, 0.313; AVIF, 1.433; AFVIF, 1.591; GoF, 0.457; and RSCR, 1.000), all of which showed the compatibility between the data and the model (Kock, 2015).

\section{Discussion}

The study aims to develop and test a structural model to predict the integration of e-learning by preservice science teachers. The overall explanatory power of our proposed model had an $R^{2}$ of $44 \%$ for e-learning integration, $R^{2}$ of $36 \%$ for skill, $R^{2}$ of $32 \%$ for intention, and $R^{2}$ of $21 \%$ for attitude. The result suggests that the model is capable of explaining a moderate proportion of variation of e-learning integration by preservice science teachers. Many perceptive results were summarised from the research model, and these are presented below.

\subsection{Factors of e-Learning Integration by Preservice Science Teachers}

The results of this study revealed that skill is the strongest predictor of e-learning integration, followed by flow experience, intention, and attitude. The relationship between skill and integration has previously been validated among practicing teachers (Knezek and Christensen, 2016). However, the predictive power of skill with an $R^{2}$ of $36 \%$ and path coefficient of $(B=0.28, p<0.01)$ in our model is higher than the predictive power of skill with an $\mathrm{R}^{2}$ of $34 \%$ and path coefficient $(B=0.26, p=p<0.01)$ (Knezek and Christensen, 2016). This result confirms the fact that preservice teachers are likely to accept e-learning integration better than the practising teachers because preservice science teachers were mostly familiarised with using e-learning in their modules (Prasojo, et al., 2018; Batane and Ngwako, 2017).

The flow experience is the second predictor of e-learning integration with path coefficient $(B=0.24, p<0.01)$. Flow experience came second because the result shows that the relationship between flow and integration is stronger through skill as a strong mediator because path coefficient between flow and skill gave the highest 
value of $(B=0.60, p<0.01)$. Hence, the indirect relationship between flow and integration is stronger than the direct relationship between flow and integration. This result is consistent with previous study (Ro, Guo and Klein, 2018) which showed that the continuous engagement of undergraduate students in the flow activity developed their skills in using e-learning, which enhanced their learning performance.

The study results also revealed that intention was the third predictor of e-learning integration with path coefficient $(B=0.22, p<0.01)$, which is inconsistent with other studies that applied TPB where it was shown that intention is the immediate predictor of integration of technology by preservice teacher (Teo and Lee, 2010; Teo, and Tan, 2012).

The study results revealed that attitude was the fourth predictor of e-learning integration with path coefficient $(B=0.13, p<0.05)$. This result contradicts previous studies which tested the WST model to predict technology integration by teachers (Knezek, Christensen and Fluke, 2003), which found that attitude was the strongest predictor of integration of technology by teachers.

The study results also revealed that flow experience predict intention with a path coefficient $(B=0.36, p<0.01)$ than attitude with a path coefficient $(B=0.19, p<0.01)$. This result is contrary to prior studies that applied TPB (Teo and Lee, 2010; Teo and Tan, 2012), which found that the attitude of preservice teacher was the immediate predictor of their intention to integrate e-learning.

The interactive effect among the factors showed that the relationship between flow and attitude with a path coefficient $(\beta=0.36, p<0.01)$ is stronger through skill with a path coefficient $(b=0.60, p<0.01)$ between flow and skill. Hence, the indirect relationship between flow and attitude is stronger than the direct relationship between flow and attitude.

\section{Study Implication, Limitation and Conclusion}

\subsection{Implication for Education}

The results of this study provide evidence that the skill of preservice science teachers was the strongest predictor of e-learning integration. Accordingly, teacher education institutions should take note of this factor and restructure their programmes in the ways that will promote e-learning integration by preservice teachers by strengthening their skills base. Thus, the focus of teacher education institutions in preparing preservice teachers to effectively integrate e-learning in their classrooms should be on improving the skills of preservice teachers to integrate e-learning to support student learning. In this regard, teacher education institutions can provide adequate and ample opportunities for preservice teachers to practise using supportive tools for e-learning in developing actual lesson plans that integrate e-learning, micro-teach those lessons in teacher education modules, and reflect on their experiences. This might help to improve and consolidate their skills towards the integration of e-learning in the classrooms.

The study results showed the significant role of flow experience in the model. It is therefore advised that teacher education institutions should invest on high-quality e-learning interactive tools that can intrinsically motivate their students to promote self-directed learning to ensure successful integration of e-learning into the curriculum.

\subsection{Limitation}

This study had some limitations that should be pointed out in this paper. First, the nature of the study sample was confined to fourth year preservice science teachers at one public university in South Africa. Additionally, data were collected from one hundred preservice science teachers that constituted a small sample size. Although, many researchers as clarified in section 4.2 agreed that small sample sizes of 30-100 are sufficient for WarpPLS technique, a bigger research sample could have yielded better results. Therefore, the results of this study cannot be generalised to the whole population of preservice science teachers in South Africa Universities. Second, the study data were collected at a specific point in time (cross-sectional study), whereas a longer term (longitudinal study) could have given a clearer picture of how the relationships among factors change over time which could have yielded improved results. Third, the data were collected through self-report measures. Although, self-report measure is often judged in the literature as the most cost-effective and valid means of collecting personal and accurate information about people (Demetriou, Ozer and Essau, 2015), it may have led to the phenomenon of 'common method variance'. This is a situation where the relationships between model 
factors are inflated as well as 'social desirability', whereby respondents provided favourable responses opposed to what they really believe or think.

\subsection{Conclusion and future research}

This study is the first to the best of our knowledge to develop and validate a model that agglutinates the most influential factors in technology integration models for predicting e-learning integration by preservice science teachers. The results of this study has demonstrated that the proposed model has a good fit to the data and supported the research hypotheses. Skill is a key factor to predict e-learning integration by preservice science teachers contrary to intention as suggested in the literature by theory of planned behaviour. This study has added significant value to the small number of studies that have so far examined factors that predict e-learning integration in the classroom. Thus, the study has revealed the order of strength among these predictors of elearning integration for teaching and learning of science subjects. Moreover, the results of this study will provide some insights for the management of e-learning in the universities and educational technology practitioners to have proper understanding of factors that predict e-learning integration before investing huge amount of money in the development of technology.

Future research may conduct longitudinal study to examine how the relationships among the factors identified in this study change over time. This could allow for tracking preservice science teachers into the first year of their teaching in schools to provide a clearer assessment of how they integrate e-learning during their beginning year of teaching in school, and beyond. Moreover, it would benefit future research to conduct meta-analysis of these factors to discover hidden evidence. In addition, the research model designed in this study may be subjected to further validation to include large sample of preservice science teachers from other universities in the country to strengthen the generalization capability of the model. Finally, future research could test the research model between preservice and in-service teachers to establish the degree to which differences may occur in predicting e-learning integration among the two groups. The results of such study would inform policy makers, teacher educators, and other education officials in their planning, designing and implementing better e-learning curricula in schools.

\section{References}

Adu Gyamfi, S., 2017. Pre-service teachers' attitude towards information and communication technology usage: A Ghanaian survey. International Journal of Education and Development using Information and Communication Technology (IJEDICT), 13 (1), pp. 52-69.

Adu Gyamfi, S., 2016. Identifying Ghanaian pre-service teachers' readiness for computer use: A Technology Acceptance Model approach. International Journal of Education and Development using Information and Communication Technology (IJEDICT), 12(2), pp. 105-122.

Afshari, M., Bakar, K. A., Su Luan, W., Samah, B. A. and Fooi, F.S., 2009. Factors affecting teachers' use of information and communication technology. International Journal of Instruction, 2(1), pp.77-104.

Agyei, D.D. and Voogt, J., 2011. Exploring the potential of the Will Skill Tool model in Ghana: Predicting prospective and practicing teachers use of technology. Computers \& Education, 56(1), pp.91-100.

Ajzen, I., 1991. The theory of planned behavior. Organizational Behavior \& Human Decision Processes, 50(2), pp.179-211.

Al-Ruz, J. A. and Khasawneh, S., 2011. Jordanian preservice teachers' and technology integration: A human resource development approach. Educational Technology and Society, 14(4), pp.77-87.

Anderson, S.E., Groulx, J.G. and Maninger, R.M., 2011. Relationships among preservice teachers' technology-related abilities, beliefs, and intentions to use technology in their future classrooms. Journal of Educational Computing Research, 45(3), pp.321-338.

Babić, S., 2012. Factors that influence academic teacher's acceptance of e-learning technology in blended learning environment. In: A. Guelfi, ed. E-Learning-Organizational Infrastructure and Tools for Specific Areas. Europe: InTech. pp.1-18.

Batane, T. and Ngwako, A., 2017. Technology use by pre-service teachers during teaching practice: Are new teachers embracing technology right away in their first teaching experience? Australasian Journal of Educational Technology, 33(1), pp. 48-61.

Bordbar, F., 2010. English teachers' attitudes toward computer-assisted language learning. International Journal of Language Studies, 4(3), pp.27-54.

Bozkurt, G., 2016. Mathematics teachers and ICT: Factors affecting pre-service use in school placements. International Journal of Research in Education and Science (IJRES), 2(2), pp. 453- 468.

Chin, W.W., 1998. The partial least squares approach to structural equation modelling. In: G.A. Marcoulides, ed. Modern Methods for Business Research. Mahwah, NJ: Lawrence Erlbaum Associates. pp.295-336.

Csikszentmihalyi, M., 1975. Beyond boredom and anxiety. San Francisco, CA: Jossey-Bass.

Csikszentmihalyi, M., 1997. Finding flow: The psychology of engagement with everyday life. New York: Basic Books. 
Davis, F. D., Bagozzi, R. P. and Warshaw, P. R., 1992. Extrinsic and intrinsic motivation to use computers in the workplace. Journal of Applied Social Psychology, 22(14), pp.1111-1132.

Demetriou, C., Ozer, B. U. and Essau, C. A., 2015. Self-Report Questionnaires. In: R. L. Cautin \& S. O. Lilienfeld, eds. The Encyclopedia of Clinical Psychology, John Wiley \& Sons, Inc. pp.1-6. doi: 10.1002/9781118625392.wbecp507

Fan, Y., Chen, J., Shirkey, G., John, R., Wu, S.R., Park, H. and Shao, C., 2016. Applications of structural equation modeling (SEM) in ecological studies: an updated review. Ecological Processes, 5(19), pp.1-12.

Fornell, C. and Larcker, D. F., 1981. Evaluating structural equation models with unobservable variables and measurement error. Journal of Marketing Research, 48, pp.39-50.

Goktas, Y., Yildirim, S. and Yildirim, Z., 2009. Main barriers and possible enablers of ICTs integration into pre-service teacher education programs. Educational Technology and Society, 12 (1), pp.193-204.

Goodhue, D.L., Lewis, W. and Thompson, R., 2012. Does PLS have advantages for small sample size or nonnormal data? MIS Quarterly, 36(3), pp.981-1001.

Guillén-Gámez, F.D., Lugones, A. and Mayorga-Fernández, M.J., 2019. ICT use by pre-service foreign languages teachers according to gender, age and motivation. Cogent Education, 6, pp.1-17.

Hair, J.F., Ringle, C.M. and Sarstedt, M., 2011. PLS-SEM: indeed a silver bullet. The Journal of Marketing Theory and Practice, 19(2), pp.139-152.

Hair, J. F., Hult, G. T. M., Ringle, C. M. and Sarstedt, M., 2014. A Primer on Partial Least Squares Structural Equation Modeling. 1st ed. Thousand Oaks: Sage.

Henseler, J., Ringle, C. M. and Sinkovics, R. R., 2009. The use of partial least squares path modeling in international marketing. Advances in International Marketing, 20, pp.277-320.

Howie, S. J. and Blignaut, A. S., 2009. South Africa's readiness to integrate ICT into mathematics and science pedagogy in secondary schools. Education and Information Technologies, 14, pp.345-363.

Jita, T., 2016. Pre-service teachers' competence to teach science through information and communication technologies in South Africa. Perspectives in Education, 34(3), pp.15- 26.

Jita, T., 2018. Exploring preservice teachers' opportunities to learn to teach science with ICTs during teaching practice. Journal of Education, 71, pp.73-90.

Joseph, S. and Olugbara, O. O., 2018. Evaluation of municipal e-government readiness using structural equation modelling technique. The Journal for Transdisciplinary Research in Southern Africa, 14(1), pp.1-10.

Kalema, B. M., Olugbara, O. O. and Kekwaletswe, R. M., 2011. The application of structural equation modeling technique to analyse students' priorities in using course management systems. International Journal of computing and ICT Research, 5(Special issue), pp. 34 - 44.

Kim, H.J. and Jang, H.Y., 2015. Motivating Preservice Teachers in Technology Integration of Web 2.0 for Teaching Internships. International Education Studies, 8(8), pp.21-32.

Kline, R.B., 2010. Principles and practice of structural equation modeling (3rd ed.). NewYork, NY: Guilford Press.

Knezek, D., Christensen, R., Hancock, R. and Shoho, A., 2000. Toward a structural model of technology integration. In: Proceeding of the Hawaii Educational Research Association Annual Conference. Honolulu, HI.

Knezek, G., Christensen, R. and Fluke, R., 2003. Testing a Will, Skill, Tool Model of Technology Integration. In: Proceeding of the Annual meeting of the American Education Research Association Conference. Chicago, Illinois, 12-25 April 2003.

Knezek, G. and Christensen, R., 2016. Extending the Will, Skill, Tool Model of Technology Integration: adding Pedagogy as a New Model Construct. Journal of Computing in Higher Education, 28(3), pp.307-325.

Kock, N., 2013. WarpPLS 4.0 User Manual. Laredo, Texas: ScriptWarp Systems.

Kock, N., 2015. WarpPLS 5.0 User Manual. Laredo, Texas: Script Warp Systems.

Lee, M.C., 2010. Explaining and predicting users' continuance intention toward e-learning: An extension of the expectationconfirmation model. Computers and Education, 54, pp.506-516.

Liao, L.F., 2006. A Flow Theory Perspective on Learner Motivation and Behavior in Distance Education. Distance Education, 27(1), pp.45-62.

Liao, H.L. and Lu, H.P., 2008. The role of experience and innovation characteristics in the adoption and continued use of elearning websites. Computer and Education, 51, pp.1405-1416.

Liu, S. H., 2016. Teacher education programs, field-based practicums, and psychological factors of the implementation of technology by pre-service teachers. Australasian Journal of Educational Technology, 32(3), pp.65 - 79.

Mofokeng P. L.S. and Mji, A., 2010. Teaching mathematics and science using computers: How prepared are South African teachers to do this? Procedia-Social and Behavioral Sciences, WCES, 2, pp. 610-1614.

Mohammad, H.A. and Nazila, B., 2015. An application of European Customer Satisfaction Index (ECSI) in business to business (B2B) context. Journal of Business and Industrial Marketing, 30(1), pp.17-31.

Morales, C., 2007. Testing Predictive Models of Technology Integration in Mexico and the United States, Computers in the Schools, 24: (3-4), pp.153-173.

Navimipour, N.J. and Soltani, Z.S., 2016. The impact of cost, technology acceptance and employees' satisfaction on the effectiveness of the electronic customer relationship management systems. Computer in Human Behaviour, 55, pp.1052-1066.

Ndlovu, N.S. and Lawrence, D., 2012. The quality of ICT use in South African classrooms. A paper presented at the Strategies to Overcome Poverty and Inequality "Towards Carnegie III" conference, September 3-7, University of Cape Town, South Africa: pp.1-26. 
Nkula, K. and Krauss, K.E.M., 2014. The integration of ICTs in marginalised schools in South Africa: Considerations for understanding the perceptions of in-service teachers and the role of training. In Steyn, J., Van Greunen, D. (eds). (2014). ICTs for inclusive communities in developing societies. Proceedings of the 8th International Development Informatics Association Conference, Port Elizabeth, South Africa: pp.241-261.

Olugbara, C. T., 2018. A study of e-learning technology integration by preservice science teachers. D.Ed. University of Zululand, South Africa.

Olugbara, C.T., Imenda, S.N., Olugbara, O.O. and Khuzwayo, H.B., 2019. Moderating effect of innovation consciousness and quality consciousness on intention-behaviour relationship in e-learning integration. Education and Information Technologies, 25, pp. 329-350.

Peng, D.X. and Lai, F., 2012. Using partial least squares in operations management research: a practical guideline and summary of past research. Journal of Operations Management, 30(6), pp.467-480.

Prasojo, L.D., Mukminin, A., Habibi, A., Marzulina, L., Sirozi, M. and Harto, K., 2018. Learning to Teach in a Digital Age: ICT Integration and EFL Student Teachers' Teaching Practices. Teaching English with Technology, 18(3), pp.18-32.

Rodriguez-Ardura, I. and Meseguer-Artola, A., 2017. Flow in e-learning: What drives it and why it matters. British Journal of Educational Technology, 48(4), pp. 899 - 915.

Ro, Y.K., Guo, Y.M. and Klein, B.D., 2018. The case of flow and learning revisited. Journal of Education for Business, 93(3), pp.128-141.

Sadaf, A., 2013. An Investigation of the Factors that Influence Preservice Teachers' Intentions and Actual Integration of Web 2.0 Technologies. Ph.D. Purdue University, Indiana.

Sadaf, A., Newby, T. J. and Ertmer, P. A., 2012. Exploring factors that predict preservice teachers' intentions to use web 2.0 technologies using decomposed theory of planned behavior. Journal of Research on Technology in Education, 15(2), pp.171-195.

Sadeck O. and Cronjé J., 2017. "A Continuum of Teachers' e-Learning Practices" The Electronic Journal of e-Learning, 15(5), pp. 396- 409.

Saltan, F. and Arslan, K., 2017. A comparison of in-service and preservice teachers' technological pedagogical content knowledge self-confidence. Cogent Education, 4(1), pp.1-12.

Sedega, B.C., Mishiwo, M., Kofi Awuitor, G. and Kafui Nyamadi, M., 2018. Pre-service teachers' perception of the use of information communication and technology (ICT) in the teaching and learning of mathematics in three colleges of education in Ghana. British Journal of Education, 6(5), pp.84-94.

Sheeran, P., 2002. Intention-behavior relations: A conceptual and empirical review. European Review of Social Psychology, 12(1), pp.1-36.

Stols, G., Ferreira, R., Pelser, A., Olivier, W. A., Van der Merwe, A., De Villiers, C. and Venter, S., 2015. Perceptions and needs of South African Mathematics teachers concerning their use of technology for instruction. South African Journal of Education, 35(4), pp.1-13.

Tarhini, A., Hone, K. and Liu, X., 2013. Factors affecting students' acceptance of e-Learning environments in developing countries: A structural equation modeling approach. International Journal of Information and Education Technology, 3(1), pp.45-59.

Teo, T., 2009. Pre-service teachers' attitudes towards computer use: A Singapore survey. Australasian Journal of Educational Technology, 24(4), pp. 413- 424.

Teo, T., 2011. Factors influencing teachers' intention to use technology: Model development and test. Computer and Education, 57, pp.2432-2440.

Teo, T. and Lee, C. B., 2010. Explaining the intention to use technology among student teachers: An application of the theory of planned behavior (TPB). Campus-Wide Information Systems, 27(2), pp.60-67.

Teo, T. and Noyes, J., 2011. An assessment of the influence of perceived enjoyment and attitude on the intention to use technology among preservice teachers: A structural equation modeling approach. Computer and Education, 57, pp.1645-1653.

Teo, T. and Tan, L., 2012. The theory of planned behaviour (TPB) and preservice teachers' technology acceptance: A validation study using structural equation modeling. Journal of technology \& Teacher Education, 20(1), pp.89-104.

Tezci, E., 2011. Factors that influence pre-service teachers' ICT usage in education. European Journal of Teacher Education, 34(4), pp. 483- 499.

Tondeur, J., Valcke, M. and Van Braak, J. A., 2008. multidimensional approach to determinants of computer use in primary education: Teacher and school characteristics. Journal of Computer Assisted Learning, 24, pp.494-506.

Tondeur, J., van Braak, J., Ertmer, P. A. and Ottenbreit-Leftwich, A., 2016. Understanding the relationship between teachers' pedagogical beliefs and technology use in education: a systematic review of qualitative evidence. Educational Technology Research and Development, 65(3), pp. 555-575.

Trevino, L. K. and Webster, J., 1992. Flow in computer-mediated communication: Electronic mail and voice mail evaluation and impacts. Communication Research, 19(5), pp.539-573.

Umugiraneza, O., Bansilal, S. and North, D., 2018. Exploring teachers' use of technology in teaching and learning mathematics in KwaZulu-Natal schools. Pythagoras, 39(1), pp.1-13.

Urbach, N. and Ahlemann, F., 2010. Structural equation modeling in information systems research using partial least squares. Journal of Information Technology Theory \& Application (JITTA), 11(2), pp.5- 40. 
Ward, G. and Overall, T. 2013. Technology Integration for pre-service Mathematics teachers: A Time-Series Study. In R. McBride \& M. Searson (eds), proceedings of society for Information Technology \& teacher Education. International Conference, 2013, 25 March, New orleans, Louisiana, United States: p. 4878- 4884.

Ziphorah, R. M., 2014. Information and communication technology integration: Where to start, infrastructure or capacity building? Procedia - Social and Behavioral Sciences, 116, pp.3649-3658. 